\title{
COMPUTATION INTELLIGENCE BASED DAILY ALGORITHMIC STRATEGIES FOR TRADING IN THE FOREIGN EXCHANGE MARKET
}

\author{
Nijolė Maknickienè ${ }^{1}$, Ieva Kekyte் ${ }^{2}$, Algirdas Maknickas ${ }^{3}$ \\ 1, 2 Department of Financial Engineering, Faculty of Business and Management, \\ Vilnius Gediminas Technical University, Saulètekio al. 11, Vilnius, Lithuania \\ ${ }^{3}$ Laboratory of Numerical Simulations/Faculty of Mechanical Engineering, \\ Vilnius Gediminas Technical University, Saulètekio al. 11, Vilnius, Lithuania \\ E-mails: 'nijole.maknickiene@vgtu.lt (correspondingauthor);2ieva.kekyte@vgtu.lt; \\ 3algirdas.maknickas@vu.lt
}

\begin{abstract}
Successful trading in financial markets is not possible without a support system that manages the preparation of the data, prediction system, and risk management and evaluates the trading efficiency. Selected orthogonal data was used to predict exchange rates by applying recurrent neural network (RNN) software based on the open source framework Keras and the graphical processing unit (GPU) NVIDIA GTX1070 to accelerate RNN learning. The newly developed software on the GPU predicted ten high-low distributions in approximately 90 minutes. This paper compares different daily algorithmic trading strategies based on four methods of portfolio creation: split equally, optimisation, orthogonality, and maximal expectations. Each investigated portfolio has opportunities and limitations dependent on market state and behaviour of investors, and the efficiencies of the trading support systems for investors in foreign exchange market were tested in a demo FOREX market in real time and compared with similar results obtained for risk-free rates.
\end{abstract}

Keywords: computation intelligence, portfolio, financial markets, investment decision, algorithmic trading.

JEL Classification: C63, G11, G17.

\section{Introduction}

The lack of information efficiency in financial markets complicates price prediction and may reduce the ability of investors to trade in financial markets profitably. Data analysis in financial markets has been an issue frequently studied. The market itself is a complex and dynamic system in which data is dense, non-stationary and chaotic, presenting a complex environment that is sensitive to various external factors.

Exchange price fluctuations are essential factors for many currency market participants. They influence decisions to cover open foreign exchange positions and can lead to non-systemic risk, reducing profits from an internationally diversified portfolio. The fluctuations become even more important because systemic volatility is most influenced by fluctuations in exchange rates (Greenwood-Nimmo, Nguyen, \& Rafferty, 2016). The exchange rate fluctuations in the foreign exchange market are different from the fluctuations in other markets in several key aspects (Barunik, Kocenda, \& Vacha, 2017):
- 24-hour operations around the world turn the currency market into a global market with a massive flow of information related to currency prices;

- Currency markets show a high degree of integration (Kitamura, 2010);

- The daily trading volumes of the foreign exchange market are many times higher than the daily trading volumes in the capital markets;

- Exchange rates are more affected by monetary policy and intervention compared to equity or bond markets (Dick, MacDonald, \& Menkhoff, 2015);

- Central bank interventions successfully affect the exchange rate volatility, especially in emerging markets (Fratzscher, Lo Duca, \& Straub, 2015).

Technical and fundamental analysis are the most common and most effective methods of currency market research. Sentimental analysis and algorithmic trading have been increasingly used for speculation and currency market investments. Applying computational (or artificial) intelligence 
in financial markets increases the speed, amount and quality of computation providing new opportunities for investors, traders, speculators and other participants of financial markets. The essence of computational intelligence in solving any problem is to study data input and output samples provided to them in such a way to determine the functional data connections, even if the underlying interfaces are unknown. Thus, artificial intelligence methods are data-based models that rely solely on data to determine their structure and parameters governing the phenomenon or system (Shahin, 2016). Many practitioners and researchers are interested in currency price forecasts, because the prospect of future trends is a prerequisite for ensuring that trading in financial markets is successful, accurate and fair (Bagheri, Peyhani, \& Akbari, 2014). Until now, economists have focused on structural patterns that were limited by the frequency of trading data; thus, these models are insignificant and inappropriate for trading use (Bekiros, 2015).

Many studies have been conducted to create well-functioning, automated trading systems (Patel, Shah, Thakkar, \& Kotecha, 2015) to establish optimal trading rules based on technical indicators in the financial market using data-based methods such as artificial intelligence, machine learning, and model recognition (Chiang, Enke, $\mathrm{Wu}, \&$ Wang, 2016). These are the most used methods in the currency market, and artificial neural networks are considered as the most effective tools for forecasting financial time series (Bagheri et al., 2014). By using artificial neural networks, the uncertainty in the financial markets is more efficiently managed due to the identification of patterns and the analysis of future trends, and this method can incorporate the latest data into the testing and update the results accordingly (Dunis, Middeleton, Karathanasopolous, \& Theofilatos, 2016).

In recent decades, artificial neural networks have become very popular in the context of financial market forecasting. The main reason is that these networks can process data that have non-linearity, discrepancy and frequent fluctuations (Liu \& Wang, 2012). Artificial beural networks are data management and self-adaptive methods that can capture nonlinear behaviour of time series without statistical data assumptions. As a result, different types of artificial neural networks have been developed and adapted to predict financial markets (Calvacante, Rodrigo, Souza, Nobrega, \& Oliveira, 2016).
Good forecasting is a necessary but insufficient condition for successful investment in the foreign exchange market. Portfolio selection is crucial to the return of an investor (Pinto, Monteiro, \& Nakao, 2011), and the selection involves complex processes of various decision-making situations (Lin \& Hsieh, 2004). Thus, to determine which types of assets should be included in the portfolio, it is necessary to evaluate a number of contradictory criteria. The portfolio's efficiency, risk, and credibility are three key characteristics that investors seek when they invest in financial markets (Rutkauskas, Stasytyte, \& Stankevičienè, 2009a; Rutkauskas, Stasytyte, \& Borisova, $2009 \mathrm{~b}$ ). Also, one of the main principles of portfolio formation remains diversification, i.e. when investors distribute their capital between different types of assets to reduce risk and increase expected returns (Gupta, Inuiguchi, \& Mehlawat, 2010; Zhu, Wang, Y., Wang, K., \& Chen, 2011). Although many studies have been performed to help decision makers in choosing portfolios, in many situations, there is a lack of comprehensive information and some uncertainty, making portfolio selection an important and complex task (Ghasemzadeh \& Archer, 2000).

The portfolio is designed to allocate the investment funds in the best manner. The portfolio concept is most efficiently managed by using modern portfolio theory as a well-established investment decision management system. The return on investment in the perspective is seen as a set of possibilities, or simply a probability distribution. In addition, modern investment portfolio helps to form an investment asset structure that is oriented towards maximising the return on capital employed, adequately responding to the interaction of investment assets and risk-taking opportunities (Rutkauskas et al., 2014).

Information technologies are increasingly being integrated into the financial field, with large computing capabilities that can perform more complex analyses by processing larger volumes of data. Financial market forecasting is of great importance in making investment decisions (Guresen, Kayakutlu, \& Daim, 2011). Unfortunately, the financial market moves randomly, is related to historical data, and is a complex and inextricable system (Lo \& MacKinlay, 2011; Manahov \& Hudson, 2014). Also, the market consists of a large number of different actors operating according to their individual economic, political and psychological factors (Ballings, Poel, Hespeels, \& 
Gryp, 2015), and these factors can increase market uncertainty and have a positive or negative impact on market prices.

Algorithms that shape a portfolio according to the needs of the investor are increasingly included in trading strategies. The importance of careful planning of all stages of trading and connecting them in one strategy has been noted (Nuti, Mirghaemi, Treleaven, \& Yingsaeree, 2011). Chaboud, Chiquoine, Hjalmarsson, and Vega (2014) investigated the impact of algorithmic trading in the foreign exchange market and found that the amount of algorithmic activity in the market has a small positive impact on market liquidity. Berutich, López, Luna, and Quintana (2016) created genetic algorithms for portfolio management and integrated them into a trading strategy. An online portfolio selection toolbox to facilitate the related research in machine learning and computational finance was also presented by $\mathrm{Li}, \mathrm{Sa}-$ hoo, and Hoi (2016). Two different portfolio construction methods for two different sets of algorithmic trading strategies were proposed by Raudys (2016), and currency pair portfolio optimisation by using algorithms was investigated by Said (2017). This author notes that algorithmic trading changes "the financial world-humans no longer monopolise financial markets."

This paper investigates four algorithmic trading strategies based on different methods of portfolio creation and compares its opportunities and limitations for investors. These trading strategies should help the investors successfully trade in the currency market, provide the investor with the desired returns and reduce investment risk.

\section{Support system for investors in foreign exchange markets}

The application of decision support systems in the financial area is not yet complete, because systems are constantly being refined and modified. Most such systems simply rely on multiple criteria-evaluation methods (Dymova, Sevastianov, \& Bartosiewicz, 2009), but some models include more advanced trading tools in analysing historical and existing data (Atsalakis \& Valavanis, 2009; Lai, Fan, Huang, \& Chang, 2009). Before the proliferation of artificial neural networks, most research on decision support systems was based on time series analysis and predicted stock price developments based on historical data. In the field of finance, models developed from time series theory such as ARIMA, ARCH, and GARCH are widely used (Vejendla \& Enke,
2013). The focus is currently on the use of artificial intelligence, and a number of such support schemes have already been developed (Ozturk, Toroslu, \& Fidan, 2016; Chiang et al., 2016; Rubell \& Jessy, 2016; Petropoulos, Chatzis, Siakoulis, \& Vlachogiannakis, 2017).

The decision support system proposed in this work consists of four main stages: preparation, forecasting, strategy setting and system assessment. The first step collects the historical data of the exchange rates required for forecasting, prepares the data for the system training, determines the parameters of the recurrent neuron network (number of neurons, iterations), and prepares for the training algorithm (ADAMS gradient Optimisation). According to the information received, the recruiting neuron network is first trained and then used to predict the currency market. The resulting forecasts are later used to formulate the strategy. The third stage of the system establishes the rules for entering the market, determines the investment portfolios calculates the exposure amounts in the portfolios. By using strategies, investors can invest in the real market and measure trading results, forecast reliability and investment risk. Afterward, the investors can assess the system.

\subsection{Keras recurrent neural network}

Forecasting exchange rates is based on computational intelligence. Keras is an open source neural network framework developed in Python programming language. Keras can work with MXNet, Deeplearning4j, Tensorflow, CNTK or Theano libraries and is designed to test neuron networks quickly. Furthermore, Keras is focussed on being minimalist, modular, and expandable. It was created as part of a study by Google's engineer François Chollet et al. that investigated the open neuro-electronic advanced robot operating system (2015). In 2017, the Google TensorFlow team decided to support Keras TensorFlow's main library. Keras has been designed as an interface that provides a higher level and more intuitive set of abstractions that makes it easy to configure neuron networks regardless of whether the backend uses them for a scientific computing library. It combines the efficient digital computing libraries Theano and TensorFlow, allowing investors to define and teach neuron network models with several short lines of code (Guli \& Pal, 2017). Keras was created to make deep learning models as quick and easy as possible for research and development through applying the following guiding principles: 
- Modulation: A model can be understood as a section or graph. All topics in the deep learning model are discrete components that can be combined independently.

- Minimalism: the library confirms the result, assures accuracy and maximises readability.

- Extensibility: new components are deliberately easy to add and use in a system designed to test and explore new ideas.

- These features of the forecasting tool are essential for investor trading in quickly changing financial markets.

\subsection{Strategies of asset allocation}

Forecasting by the Keras recurrent neural network uses the high-low distribution method (Stankevičienè, Maknickienè, \& Maknickas, 2014).

According to the obtained Keras recurrent neural network exchange rate forecasts, four currency trading strategies that have four different two-dimension (profitability-risk) portfolios were constructed.

- The Controlling portfolio is established by allocating all funds equally to all currency pairs in the portfolio.

- The Optimal portfolio is made by dividing the investment funds for four assets by weights, and predicted profitability and the risk determine the weights. The portfolio is then constructed from $i$ exchange rates according to the system of equations (Stankevičienè, Maknickienè, \& Maknickas, 2017):

$$
\left\{\begin{array}{l}
\max \sum_{i=1}^{n} W_{i} p_{p i} ; \\
\min \sum_{i=1}^{n} W_{i} p_{l i} .
\end{array}\right.
$$

Where $W_{i}$ represents the weight of asset $i$ in the portfolio, $p_{p i}$ represents the probability of $i$ asset profit and $p_{l i}$ represents the probability of $i$ asset lost.

The Orthogonal optimal portfolio is built in the same manner (1 formula) as the optimal portfolio, but the orthogonal portfolio assets must satisfy the orthogonality condition (Roll, 1980)

$$
\sum_{i, j}^{n} r_{i j} \sigma_{i} \sigma_{j}=0
$$

where $r_{i j}$ represents the correlation between assets $i$ and $j, \sigma_{i}$ represents the standard deviation of asset $i$, and $\sigma_{j}$ represents the standard deviation of asset $j$.

The Best from 10 portfolio comprises the entire invested amount by investing in the highest growth-boosting currencies. Keras recurrent neural network gives high and low prediction distribution for ten assets. The best exchange rates are selected by the following system of equations:

$$
\left\{\begin{array}{c}
\max \sum_{i=1}^{n} W_{i} p_{p i} ; \\
W_{i}>W_{\max } d,
\end{array}\right.
$$

where $W_{i}$ represents the weight of asset $\mathrm{i}$ in the portfolio, $p_{p i}$ represents the probability of $i$ asset profit, $d$ represents the multiplier equal to 0.8 or 0.9 , making the portfolio use more than one tool.

Four portfolios were tested in daily trading based on exchange rates in real time. In addition, portfolio efficiency was evaluated by using Sharpe index (Sharpe, 1994), standard deviation and overall classifier accuracy (OCA) (Sharda, Delen, \& Turban, 2013).

\section{Investigation of trading strategies in real time}

Algorithmic trading connects historical data, spot decisions and the perspectives of market changes. Predictions were determined by Keras recurrent networks calculations made every trading day based on historical data.

Exchange rate forecasts were calculated daily using currency recurrences of neural networks. When the maximum and minimum daily values of 98 days were selected, two sets of expected values were obtained for the next day. These divisions provide additional options for investors. They can choose different expected changes to the day depending on the probabilities presented. For example, the decision to buy or sell is determined by the value of the exchange rate at the current moment in relation to the projected values. Probability calculation methodology is illustrated by the probability distribution of the forecasting day of 2017-11-29. Pictures provided by Keras (Figures 1, 2, 3, and 4) present the high, low distributions and their intersection. Vertical lines represent the known prices, red lines represent low price from the previous day, green lines represent the high price from the previous day and 
blue lines represent the price at the time of the data collection.

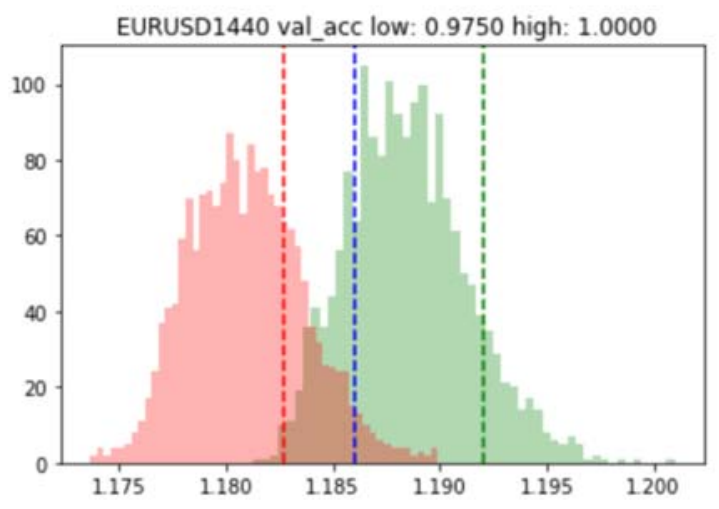

Figure 1. Distributions of minimum and maximum expected values for the EUR/USD exchange rate for the day of 2017-11-29 (source: made by authors)

The standard deviation of the minimum value for the EUR / USD expected value (Figure 1. pink column) is 0.0027 , and the moda is 1.1797 . The standard deviation of the maximum expected value distribution (Figure 1, green column) is 0.0028 , and the moda is 1.1858 . The current moment value (closing value 2017-11-29) is 1.1861, and it is to the right of the minimum and maximum mods. A decision must be made to sell, because the likelihood of success when choosing to buy is less than choosing to sell. The decision to buy in this case is risky.

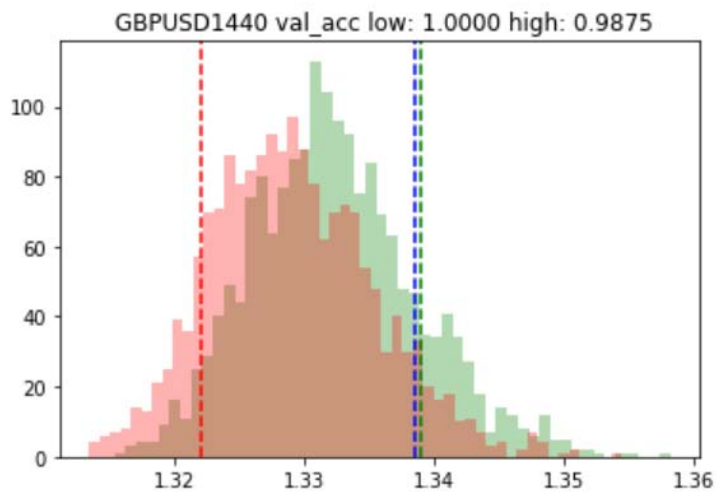

Figure 2. Distributions of minimum and maximum probable values for the GBP/USD exchange rate for the day of 2017-11-29 (source: made by authors)

Similarly, with a pair of GBP/USD currency, with a standard deviation of the minimum probable value distributions (Figure 2, pink column) of 0.0063 , and the moda is 1.3248 . The standard deviation of the maximum expected value distribution (Figure 2, green column) is 0.0064 , and the moda is 1.3224 . The current moment value (closing value 2017-11-29) is 1.3386 and is to the right of the minimum and maximum mods, so the decision to buy in this case is also risky.

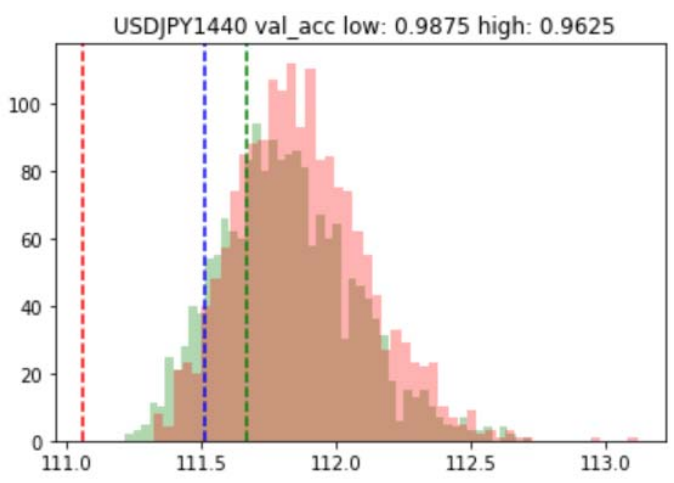

Figure 3. USD/JPY exchange rate minima and maximum expected values for the day of 2017-11-29 (source: made by authors)

The standard deviation of the USD/JPY minimum pair of distributions (Figure 3, pink column) is 0.2417 , and the moda is 112.743 . The standard deviation of the maximum expected value distribution (Figure 3, green column) is 0.2485 , and the moda is 112.038 . The current moment value (closing value 2017-11-29) is 111.509 and is to the left of the minimum and maximum mods, so a decision is made to buy, while the decision to sell becomes risky.

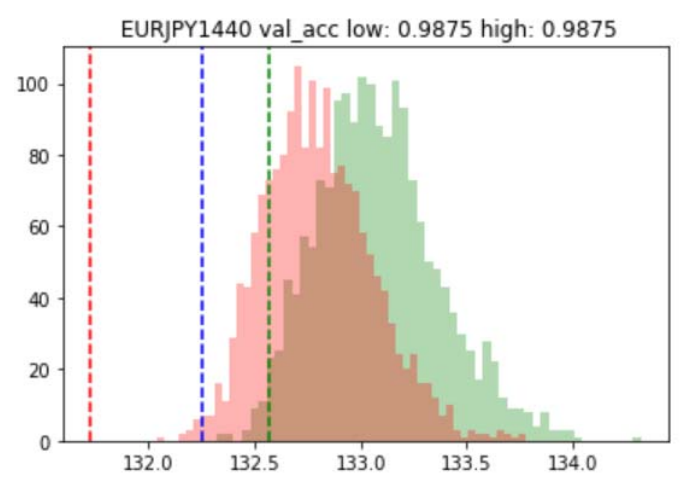

Figure 4. Distributions of minimum and maximum expected values for the EUR/JPY exchange rate for the day of 2017-11-29 (source: made by authors)

The standard deviation of the EUR/JPY minimum expected values distribution (Figure 4, pink column) is 0.2577 , and the moda is 132.752 . The standard deviation of the maximum probable value distribution (Figure 4, green column) is 0.2882 , moda is 132.609 . The current moment value (closing value 2017-11-29) is 132.253 and is left of the minimum and maximum mods, so a buy decision is made. The bounded area of the 
maximum values distribution to the right of the current moment value is greater than the left. The chance of success when choosing to buy is higher than choosing to sell. Thus, the decision to sell is risky.

Forecasting based on high and low probability distributions has additional information. Standard deviation explains the risk of investment, while values higher then $20 \%$ from the closing value of the previous day shows very high risk and can be explained by the changes of trends in the financial market. Distributions are multimodal, but the main moda represents the most expected forecasting value.

According to these forecasts, four different portfolios were constructed every trading day. Trading decisions were then tested using the Oanda demo platform.

The Control portfolio was constructed from four main exchange rates (EUR/USD, USD/JPY, USD/CHF and GBP/USD) by allocating assets into four equal parts (e.g. see Figure 5) according to the following forecasting recommendations: "buy" if predictions shows exchange rate growth and "sell" if the predictions show exchange rate decline.

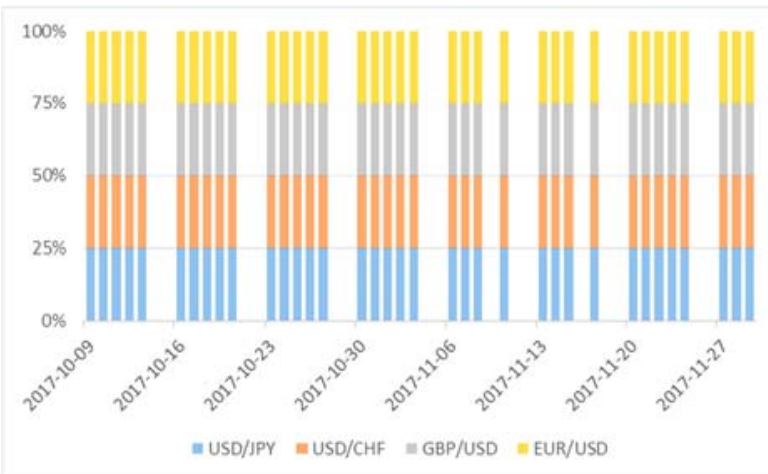

Figure 5. Asset allocation in the Control portfolio (source: made by authors)

The Optimal portfolio was constructed from some exchange rates by Eq. (1) according to probabilities from high and low forecasting distributions (e.g. see Figure 6). Not equally distributing assets increases the risk, but this strategy also limits growth opportunities.

The Orthogonal Optimal portfolio was constructed from four exchange rates selected by 2 formula: EUR/GBP, AUD/USD, USD/CAD, EUR/USD. Assets (e.g. see Figure 7) were not equally distributed by calculating every trading day by 1 Formula. Independent exchange rates are more useful in unstable markets.

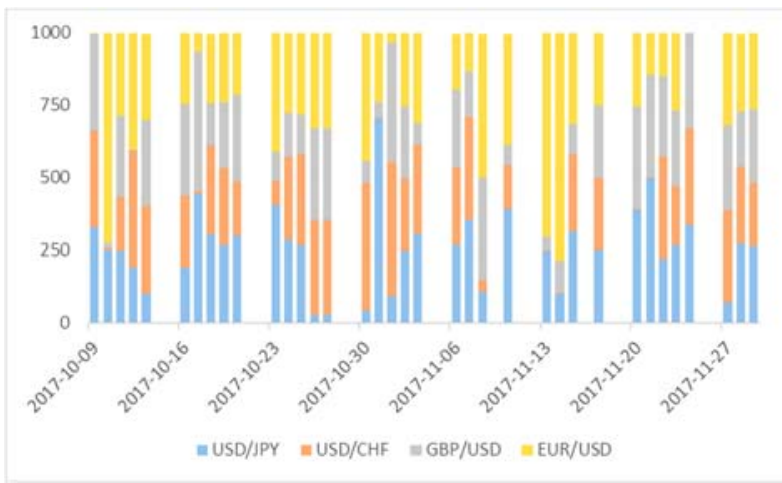

Figure 6. Asset allocation of the Optimal portfolio (source: made by authors)

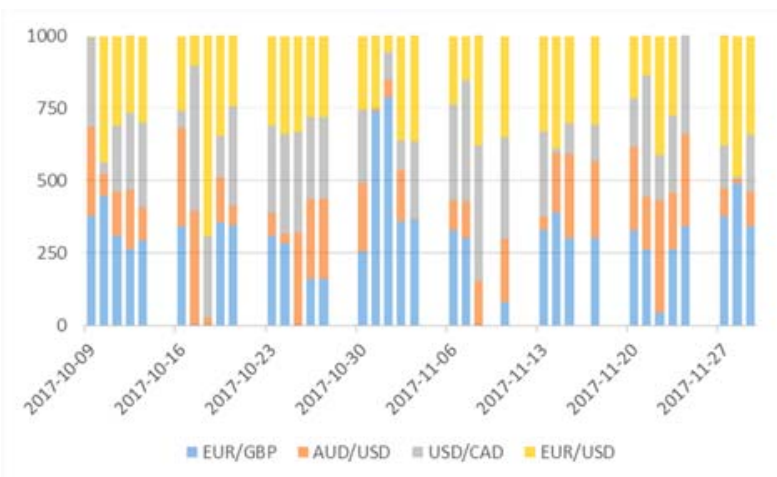

Figure 7. Asset allocation of the Orthogonal portfolio (source: made by authors)

The Best from 10 portfolio was built from ten exchange rates (EUR/USD, USD/JPY, USD/CHF and GBP/USD, EUR/GBP, AUD/USD, USD/ $\mathrm{CAD}, \mathrm{NZD} / \mathrm{CAD}, \mathrm{GBP} / \mathrm{AUD}$ ) by using three formulas. Allocating assets in more parts (e.g., see Figure 8) means higher diversification.

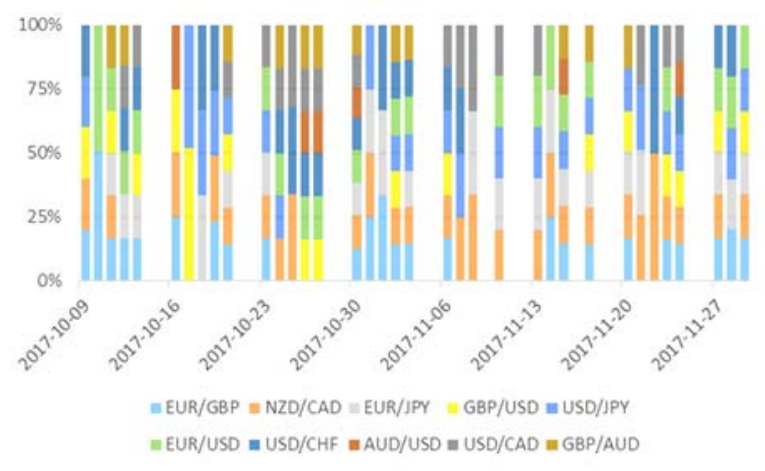

Figure 8. Asset allocation in the Best from 10 portfolio (source: made by authors)

All portfolios were used over a period of two months at the same time. Redeployment of investment funds was made every trading day according to predictions made by the Keras recurrent neural network. The portfolios constructed by the four trading methods are compared in Table 1. 
Table 1. Portfolio performance comparison (source: made by authors)

\begin{tabular}{|l|c|c|c|c|}
\hline & $\begin{array}{c}\text { Control- } \\
\text { ling }\end{array}$ & $\begin{array}{c}\text { Opti- } \\
\text { mal }\end{array}$ & $\begin{array}{c}\text { Ortho- } \\
\text { gonal }\end{array}$ & $\begin{array}{c}\text { Best } \\
\text { from 10 }\end{array}$ \\
\hline $\begin{array}{l}\text { Average } \\
\text { profit } \%\end{array}$ & 0.1 & 0.3 & 0.4 & 0.9 \\
\hline$\sigma$ & 71.59 & 93.24 & 109.74 & 65.55 \\
\hline $\begin{array}{l}\text { Sharpe } \\
\text { index }\end{array}$ & -1.08 & 3.72 & 7.32 & 8.62 \\
\hline OCA & $61.9 \%$ & $64 \%$ & $65 \%$ & $68 \%$ \\
\hline
\end{tabular}

Three portfolios, Optimal, Orthogonal optimal and Best from 10, outperformed the Control portfolio trading. The best profit, Sharpe ratio and OCA results were achieved by the Best from 10 portfolio, but this portfolio requires more computational resources. In addition, trading with the Optimal and Orthogonal optimal portfolios had the highest risk. Methods of portfolio construction integrated in the support system for investors in exchange markets provide new knowledge about algorithmic trading strategies.

\section{Conclusions}

The short-term forecast is usually much more accurate than the long-term, so portfolio reshaping at a certain frequency is a very important part of a support system for investors. Algorithms of asset allocation methods added to computational intelligence based on predicted exchange rates gives new opportunities in the creation of trading strategies.

Forecasting based on high and low probability distributions allows risk to be considered in making decisions. Throughout the whole trading period, the standard deviation of probability distributions was in range $(0.0005 ; 0.32)$.

Four portfolio daily reshaping methods were compared to find priorities and limitations. The best results were obtained by using the Best from 10 method that uses forecasts of ten different exchange rates and looks for the optimal variant. The construction of portfolio varied from 2 to 8 rates, and this method shows the best portfolio comparison values (profit: $0.9 \%$; Sharpe ratio: 8.62; and OCA:68\%). However, this method requires the more computational and time resources. Next in the range is orthogonal $(0.4 \% ; 7.32 ; 65 \%)$, then optimal $(0.3 \% ; 3.72 ; 64)$. The asset allocation of both these portfolios varied only from four exchange rates selected by popularity or interdependence; thus, the results are very similar. The controlling portfolio also showed profitable results $(0.1 \% ;-1.06 ; 61 \%)$. Forecasting the four exchange rates requires less computational and time resources then used in calculating the The Best from 10 portfolio.

All these results were reached independently by real-time demo platforms by two different traders, so they were obtained in equal market and behavioural conditions. Algorithms created for reshaping of exchange rates portfolio can be integrated in trading strategies, support systems for investors and trading robots.

\section{References}

Atsalakis, G. S., \& Valavanis, K. P. (2009). Forecasting stock market short-term trends using a neuro-fuzzy based methodology. Expert Systems with Applications, 36(7), 10696-10707.

https://doi.org/10.1016/j.eswa.2009.02.043

Bagheri, A., Peyhani, M. H., \& Akbari, M. (2014). Financial forecasting using ANFIS networks with Quantum-behaved Particle Swarm Optimization. Expert Systems with Applications, 41(14), 6235-6250.

https://doi.org/10.1016/j.eswa.2014.04.003

Ballings, M., Poel, D., Hespeels, V. D., \& Gryp, N. R. (2015). Evaluating multiple classifiers for stock price direction prediction. Expert Systems with Applications, 42(20), 7046-7056. https://doi.org/10.1016/j.eswa.2015.05.013

Barunik, J., Kocenda, E., \& Vacha, L. (2017). Asymmetric volatility connectedness on the forex market. Journal of International Money and Finance, 77, 39-56. https://doi.org/10.1016/j.jimonfin.2017.06.003

Bekiros, S. D. (2015). Heuristic learning in intraday trading under uncertainty. Journal of Empirical Finance, 30, 34-49. https://doi.org/10.1016/j.jempfin.2014.11.002

Berutich, J. M., López, F., Luna, F., \& Quintana, D. (2016). Robust technical trading strategies using GP for algorithmic portfolio selection. Expert Systems with Applications, 46, 307-315. https://doi.org/10.1016/j.eswa.2015.10.040

Calvacante, C. R., Rodrigo, C. B., Souza, V. L. F., Nobrega, J. P., \& Oliveira, A. L. I. (2016). Computational intelligence and financial markets: A survey and future directions. Expert Systems with Applications, 55, 194211. https://doi.org/10.1016/j.eswa.2016.02.006

Chaboud, A. P., Chiquoine, B., Hjalmarsson, E., \& Vega, C. (2014). Rise of the machines: Algorithmic trading in the foreign exchange market. The Journal of Finance, 69(5), 2045-2084. https://doi.org/10.1111/jofi.12186

Chiang, W. Ch., Enke, D., Wu, T., \& Wang, R. (2016). An adaptive stock index trading decision support system. Expert Systems with Applications, 59, 195-207.

Chollet, F. (2015). Keras. GitHub. Retrieved from https://github.com/fchollet/keras

Dick, C. D., MacDonald, R., \& Menkhoff, L. (2015). Exchange rate forecasts and expected fundamentals. Journal of International Money and Finance, 53(C), 235-256. https://doi.org/10.1016/j.jimonfin.2015.02.002 


\section{COMPUTATION INTELLIGENCE BASED DAILY ALGORITHMIC STRATEGIES FOR TRADING IN THE FOREIGN EXCHANGE MARKET}

Dunis, C. L., Middeleton, P. W., Karathanasopolous, A., \& Theofilatos, K. (Eds.) (2016). Artificial intelligence in financial markets. Cutting-edge applications for risk management, portfolio optimization, and economics. Palgrave Macmillan. $344 \mathrm{p}$.

https://doi.org/10.1057/978-1-137-48880-0

Dymova, L., Sevastianov, P., \& Bartosiewicz, P. A. (2009). New approach to the rule-base evidential reasoning: stock trading expert system application. Expert Systems with Applications, 37(8), 5564-5576. https://doi.org/10.1016/j.eswa.2010.02.056

Fratzscher, M., Lo Duca, M., \& Straub, R. (2016). ECB unconventional monetary policy: Market impact and international spillovers. IMF Economic Review, International Monetary Fund, 64(1), 36-74.

Ghasemzadeh, F., \& Archer, N. P. (2000). Project portfolio selection through decision support., Decision Support Systems, 29(1), 73-88.

https://doi.org/10.1016/S0167-9236(00)00065-8

Greenwood-Nimmo, M., Nguyen, V. H., \& Rafferty, B. (2016). Risk and return spillovers among the G10 currencies. Journal of Financial Markets, 31(C), 43-62. https://doi.org/10.1016/j.finmar.2016.05.001

Guli, A., \& Pal, S. (2017). Deep learning with Keras. Packt Publishing, Birmingham, UK, 490.

Gupta, P., Inuiguchi, M., \& Mehlawat, M. K. (2010). A hybrid approach for constructing suitable and optimal portfolios. Expert Systems with Applications, 36(5), 5620-5632. https://doi.org/10.1016/j.eswa.2010.10.073

Guresen, E., Kayakutlu, G., \& Daim, T. U. (2011). Using artificial neural network models in stock market index prediction. Expert Systems with Applications, 38(8), 10389-10397.

https://doi.org/10.1016/j.eswa.2011.02.068

Kitamura, Y. (2010). Testing for intraday interdependence and volatility spillover among the euro, the pound and the Swiss franc markets. Research in International Business and Finance, 24(2), 158-171. https://doi.org/10.1016/j.ribaf.2009.11.002

Lai, R. K., Fan, C. Y., Huang, W. H., \& Chang, P. C. (2009). Evolving and clustering fuzzy decision tree for financial time series data forecasting. Expert Systems with Applications, 36(2), 3761-3773. https://doi.org/10.1016/j.eswa.2008.02.025

Li, B., Sahoo, D., \& Hoi, S. C. (2016). OLPS: a toolbox for on-line portfolio selection. Journal of Machine Learning Research, 17(35): 1-5.

Lin, C. H., \& Hsieh, P. J. (2004). A fuzzy decision support system for strategic portfolio management. Decision Support Systems, 38(3), 383-398. https://doi.org/10.1016/S0167-9236(03)00118-0

Liu, F., \& Wang, J. (2012). Fluctuation prediction of stock market index by Legendre neural network with random time strength function. Neurocomputing, 83, 12-21. https://doi.org/10.1016/j.neucom.2011.09.033

Lo, A. W., \& MacKinlay, A. C. (2011). A non-random walk down wall street. Princeton, New Jersey: Princeton University Press. 448 p. https://doi.org/10.1515/9781400829095

Manahov, V., \& Hudson, R. (2014). A note on the relationship between market efficiency and adaptability - new evidence from artificial stock markets. Expert Systems with Applications, 41(16), 7436-7454.

https://doi.org/10.1016/j.eswa.2014.06.004
Nuti, G., Mirghaemi, M., Treleaven, P., \& Yingsaeree, C. (2011). Algorithmic trading. Computer, 44(11), 61-69. https://doi.org/10.1109/MC.2011.31

Ozturk, M., Toroslu, H. I., \& Fidan, G. (2016). Heuristic based trading system on Forex data using technical indicator rules. Applied Soft Computing, 43, 170-186. https://doi.org/10.1016/j.asoc.2016.01.048

Patel, J., Shah, S., Thakkar, P., \& Kotecha, K. (2015). Predicting stock and stock price index movement using Trend Deterministic Data Preparation and machine learning techniques. Expert Systems with Applications, 42(1), 259-268. https://doi.org/10.1016/j.eswa.2014.07.040

Petropoulos, A., Chatzis, P. S., Siakoulis, V., \& Vlachogiannakis, N. (2017). A stacked generalization system for automated FOREX portfolio trading. Expert Systems with Applications, 90, 290-302. https://doi.org/10.1016/j.eswa.2017.08.011

Pinto, D. D. D., Monteiro, J. G. M. S., \& Nakao, E. H. (2011). An approach to portfolio selection using an ARX predictor for securities' risk and return. Expert Systems with Applications, 38(12), 15009-15013. https://doi.org/10.1016/j.eswa.2011.05.046

Raudys, A. (2016, July). Portfolio of global futures algorithmic trading strategies for best out-of-sample performance. In International Conference on Business Information Systems (pp. 424-435). Springer, Cham. https://doi.org/10.1007/978-3-319-39426-8_33

Roll, R. (1980). Orthogonal portfolios. Journal of Financial and Quantitative Analysis, 15(5), 1005-1023. https://doi.org/10.2307/2330169

Rubell, M. L. G., \& Jessy, J. C. (2016). A multiple fuzzy inference systems framework for daily stock trading with application to NASDAQ stock exchange. Expert Systems with Applications, 44, 13-21.

https://doi.org/10.1016/j.eswa.2015.08.045

Rutkauskas, A. V., Stasytytė, V., \& Borisova, J. (2009b). Adequate portfolio as a conceptual model of investment profitability, risk and reliability adjustment to investor's interests. Economics \& Management, (14), 1170-1174.

Rutkauskas, A. V., Stasytytè. V., \& Stankevičienė, J. (2009a). Profit, riskness and reliability - three-dimensional base for investment decisions management. In Modeling and Analysis of Safety and Risk in Complex Systems, Proceedings of the Ninth International Scientific School MA SR, 7-11 July 2009, Saint Petersburg, Russia. SUAI, 105-110.

Rutkauskas, A.V., Ignotas, A., Stasytytè, V., Kvieskienè, G., Celiešienè, E., Mikulskienè, B., Pitrènaitè-Žilènienè, B., Navickas, V., Ruškytè, D., \& Podvezko, V. (2014). Ǐžvalgi investavimo strategija puoselejant universaluji pletros tvaruma: monografija. Vilnius: $\mathrm{UAB}$ „BMK leidykla“. $362 \mathrm{p}$.

Said, S. (2017). Currency pair portfolio optimization through the use of algorithmic coding: Bachelor's thesis. University of Malta.

Shahin, M. A. (2016). State-of-the-art review of some artificial intelligence applications in pile foundations, Geoscience Frontiers, 7(1), 33-44. https://doi.org/10.1016/j.gsf.2014.10.002

Sharda, R., Delen, D., \& Turban, E. (2013). Business intelligence: A managerial perspective on analytics ( $3^{\text {rd }} \mathrm{ed}$.). Prentice Hall Press Upper Saddle River.

Sharpe, W. F. (1994). The sharpe ratio. The Journal of Portfolio Management, 21(1), 49-58. 
https://doi.org/10.3905/jpm.1994.409501

Stankevičienè, J., Maknickienè, N., \& Maknickas, A. (2014). Investigation of exchange market prediction model based on high-low daily data. In The $8^{\text {th }}$ International Scientific Conference "Business and Management 2014”, 15-16 May, 2014, Vilnius, Lithuania, 320-328.

Stankevičienè, J., Maknickienė, N., \& Maknickas, A. (2017). High-low strategy of portfolio composition using Evolino RNN ensembles. Inzinerine Ekonomika-Engineering Economics, 28(2), 162-169.

https://doi.org/10.5755/j01.ee.28.2.15852
Vejendla, A., \& Enke, D. (2013). Performance evaluation of neural networks and GARCH models for forecasting volatility and option strike prices in a bull call spread strategy. Journal of Economic Policy and Research, $8(2), 1-19$.

Zhu, H., Wang, Y., Wang, K., \& Chen, Y. (2011). Particle swarm optimization (PSO) for the constrained portfolio optimization problem. Expert Systems with Applications, 38(8), 10161-10169. https://doi.org/10.1016/j.eswa.2011.02.075 